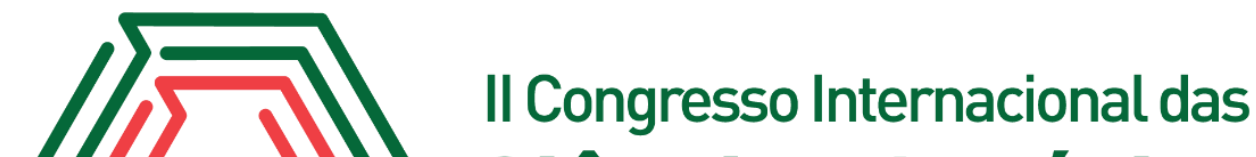 Ciências Agrárias COINTER - PDVAgro 2017
}

\section{CARBONO DA BIOMASSA MICROBIANA EM DIFERENTES SISTEMAS DE MANEJO NO BIOMA CERRADO}

\author{
Apresentação: Pôster \\ Wesley dos Santos Souza ${ }^{1}$; Patrícia Carvalho da Silva²; Tamires Soares da Silva ${ }^{3}$; Manoel \\ Ribeiro Holanda Neto ${ }^{4}$
}

\section{Introdução}

Devido ao crescimento populacional tem surgido a necessidade de se aumentar a quantidade de alimentos produzidos no mundo e no Brasil, diante disso há necessidade de se abrir novas áreas, com isso o cerrado brasileiro vem ganhando destaque, pois novas áreas estão sendo abertas para que se possa aumentar a produção de alimento. O cerrado apresenta características físicas favoráveis para a utilização agrícola, porem possui baixa fertilidade natural, e com a ocorrência da retirada da vegetação nativa presente no local para a implantação de qualquer sistema de exploração agrícola pode causar alterações nos atributos biológicos do solo, pois eles são bastante sensíveis a mudanças no ambiente. Diante disso para manter a qualidade do solo se faz necessário adoção de um sistema de manejo ideal.

Neste contexto, o presente trabalho objetivou pesquisar e aperfeiçoar conhecimentos acerca da qualidade do solo através da avaliação do carbono da biomassa microbiana em diferentes sistemas de manejo em área de cerrado.

\section{Fundamentação Teórica}

O uso sustentável dos recursos naturais, especialmente do solo e da água, tem-se constituído em tema de crescente relevância, em razão do aumento das atividades antrópicas, consequentemente, cresce a preocupação com o uso sustentável e a qualidade desses recursos (ARAÚJO et al. 2007). Neste sentido, uma das formas de se melhorar a qualidade do solo envolve a adoção de sistemas conservacionistas, como o sistema de plantio direto (GODSEY et al., 2007).

\footnotetext{
${ }^{1}$ Mestrado em Ciência do Solo, Universidade Federal do Ceará, agrowesley95@gmail.com

${ }^{2}$ Mestrado em Produção Sustentável, Universidade de Brasília, patriciacarvalhoagro@gmail.com

${ }^{3}$ Graduação em Agronomia, Universidade Estadual do Piauí, tamyres-soares@hotmail.com

${ }^{4}$ Professor Assistente I-DE, Universidade Estadual do Piauí, mrholandaneto@hotmail.com
} 
O monitoramento da qualidade do solo pode ser realizado a partir de indicadores microbiológicos, tais como a atividade e a biomassa microbiana, estes indicadores podem fornecer informações sobre a dinâmica da matéria orgânica do solo e, consequentemente, refletir sobre tendências de mudanças que estão ocorrendo em curto e longo período (ARAÚJO et al., 2008). Devido à importância dos indicadores biológicos para os processos edáficos, estudos que relacionam a quantidade de biomassa e atividade microbiana do solo podem fornecer subsídios para o planejamento correto do sistema de manejo do solo e no monitoramento dos processos edáficos (SAMPAIO et al., 2008).

\section{Metodologia}

O trabalho foi realizado na Fazenda São Marcos, localizada no município de Gilbués-PI (9'49'54' S e 4520'38' W). O local de estudo encontra-se a $481 \mathrm{~m}$ de altitude, inserida na região do bioma cerrado, região sudoeste do estado do Piauí. O clima da área pesquisada é tropical quente e úmido, com estação seca bem definida (Aw segundo a classificação de Köppen), registradas temperatura e precipitação média anual de $26^{\circ} \mathrm{C}$ e $1000 \mathrm{~mm}$, respectivamente (Pragana, 2011). $\mathrm{O}$ solo é classificado como Latossolo Amarelo distrófico, textura média (EMBRAPA, 2013).

Foram estudadas áreas de cerrado com Sistema de Plantio Convencional (SPC), Sistema Plantio Direto com 6 e 8 anos de adoção (SPD6 e SPD8), Sistema Plantio Direto 17 anos de adoção, mais Integração Lavoura Pecuária nos últimos três anos (SPD17+ILP3) e Sistema de Integração Pecuária e Floresta (IPF) e ainda foi selecionada e avaliada uma área sob Vegetação Nativa de Cerrado (VNC), como referência de um sistema em estado de equilíbrio. No mês de outubro do ano de 2015 em cada sistema foram abertas cinco trincheiras para a coleta de amostras de solos nas profundidades de $0-5,5-10$ e $10-20 \mathrm{~cm}$. Logo após a coleta, as amostras foram levadas para o laboratório e preservadas em geladeira a $\pm 4^{\circ} \mathrm{C}$.

O carbono da biomassa microbiana foi determinado pelo método da irradiação-extração, utilizando forno de microondas (ISLAM e WEIL, 1998), quantificado por meio de procedimento por oxidação úmida (YEOMANS e BREMNER, 1988).

Os dados foram submetidos à análise de variância e as médias foram comparadas pelo teste Tukey $(\mathrm{p}<0,05)$, utilizando o programa computacional Assistat 7.7. 


\section{Resultados e Discussões}

Os diferentes sistemas de manejo do solo promoveram alterações significativas nas variáveis analisadas, indicando que a mudança da vegetação nativa para um sistema de manejo do solo causa alterações nos atributos microbiológicos do solo, principalmente por se tratarem de atributos sensíveis a mudanças no solo. Carvalho (2005) relatou que não se pode esperar que um ecossistema que tenha sofrido algum tipo de interferência antrópica apresente o mesmo desempenho de um ecossistema natural, na decomposição dos resíduos vegetais, na reciclagem de nutrientes, na conservação da água e no fluxo de gases.

Tabela 1. Carbono da Biomassa Microbiana $\left(\mathrm{C}_{\mathrm{mic}}\right)$, em diferentes sistemas de manejo do solo no cerrado. Fonte: Própria

\begin{tabular}{ccccccc}
\hline Profundidade & VNC & SPC & IPF & SPD6 & SPD8 & SPD17+ILP3 \\
\hline \multirow{7}{*}{$0-5 \mathrm{~cm}$} & $571.26 \mathrm{ab}$ & $287.32 \mathrm{abc}$ & $615.21 \mathrm{a}$ & $358.31 \mathrm{abc}$ & $192.67 \mathrm{bc}$ & $152.11 \mathrm{c}$ \\
$5-10 \mathrm{~cm}$ & $662.53 \mathrm{a}$ & $263.66 \mathrm{~b}$ & $452.95 \mathrm{ab}$ & $392.11 \mathrm{ab}$ & $263.66 \mathrm{~b}$ & $336.97 \mathrm{ab}$ \\
$10-20 \mathrm{~cm}$ & $398.87 \mathrm{a}$ & $270.42 \mathrm{a}$ & $510.42^{\mathrm{a}}$ & $327.88 \mathrm{a}$ & $341.40 \mathrm{a}$ & $348.16 \mathrm{a}$
\end{tabular}

Medias seguidas da mesma letra na linha não diferem estatisticamente entre si, pelo teste de Tukey a 5\% de probabilidade. VNC- Vegetação Nativa de Cerrado, SPC- Sistema de Plantio Convencional, IPF- Integração Pecuária floresta, SPD6- Sistema de Plantio Direto com 6 anos de adoção, SPD8- Sistema de Plantio Direto com 8 anos de adoção, SPD16- Sistema de Plantio Direto com 16 anos de adoção.

A área avaliada sob Vegetação Nativa de Cerrado (VNC) e a Integração Pecuária Floresta (IPF) foram os que apresentaram os maiores valores de Carbono da Biomassa Microbiana $\left(\mathrm{C}_{\mathrm{mic}}\right)$, onde os maiores valores na primeira profundidade (0-5 $\mathrm{CM})$ e na última profundidade estudadas foram encontrados na IPF em que a rizosfera das duas culturas pode ter contribuído pela maior disponibilidade de substratos orgânicos para a microbiota do solo (OLIVEIRA; MENDES; VIVALDI, 2001). Justifica-se também que este pode ser atribuído a ausência do preparo do solo, tornando-os mais próximos das condições naturais, resultando em maior presença de raízes, que são responsáveis pela entrada de substratos carbonados, promovem a diversidade de espécies e favorecem o desenvolvimento microbiano (MENDES et al., 2001).

A menores quantidade de Carbono da Biomassa Microbiana foram encontradas nos sistemas de plantio direto e no sistema de plantio convencional, sistemas em que ocorre o cultivo de grandes culturas como soja e milho. Além dos efeitos associados à remoção da vegetação nativa e intensidade de manejo do solo, as reduções no $\mathrm{C}_{\text {mic }}$ nesses sistemas, possivelmente, também refletiram alterações associadas à quantidade e à qualidade dos resíduos vegetais disponíveis à 
microbiota (SILVA et al., 2009). Onde os restos vegetais tinham sido depositados no solo há bastante tempo, o que pode ter ocasionado uma diminuição nos teores de carbono, pela quantidade de material orgânico presente no solo está em pequena quantidade, por já ter sofrido decomposição de grande parte do material depositado.

\section{Conclusões}

A produção de culturas anuais sob o Sistema de Plantio Direto (SPD) e Sistema de Plantio Convencional (SPC) promoveram, redução nos teores de carbono da biomassa microbiana, enquanto que o Sistema Integração Lavoura Pecuária manteve teores próximos ao da Vegetação Nativa.

O aumento do tempo de utilização do solo com sistema de plantio direto ocasionou a diminuição do teor de Carbono da Biomassa Microbiana na primeira profundidade $(0-5 \mathrm{~cm})$.

\section{Referências}

ARAÚJO, A. S. F.; MONTEIRO, R. T. R. Indicadores biológicos de qualidade de solo. Uberlândia. Bioscience Journal. v.23, n.3. p. 66-75, 2007.

ARAÚJO, A. S. F.; SANTOS, B. B.; MONTEIRO, R. T. R. Responses of soil microbial biomass and activity for practices of organic and conventional farming systems in Piauí state, Brazil. European Journal of Soil Biology, v. 44, n. 2, p. 225-230, 2008.

CARVALHO, F. Atributos bioquímicos como indicadores da qualidade de solo em florestas de araucária angustifólia. 2005. 79 p. Dissertação (Mestrado em Solos). Escola Superior de Agricultura Luiz de Queiroz, Piracicaba, 2005.

EMBRAPA - Empresa Brasileira de Pesquisa Agropecuária. Solos. Sistema brasileiro de classificação de solos. ed. Rio de Janeiro: Embrapa Solos, 2013. 353p.

GODSEY, C. B.; PIERZYNSKI, G. M.; MENGEL, D. B.; LAMOND, R. E. Changes in soil pH, organic carbon, and extractable aluminum from crop rotation and tillage. Soil Science Society of America Journal, v. 71, n. 03, p. 1032-1044, 2007.

ISLAM, K.R.; WEIL, R.R. Mcrowave irradiation of soil for routine measurremente of microbial biomass carbon. Biology and Fertility of Soils. v: 27: 408-416, 1998.

MENDES, I.C. \& VIVALDI, L.A. Dinâmica da biomassa e atividade microbiana em uma área sob mata de Galeriana região do Distrito Federal. In: RIBEIRO, J.F.; FONSECA, C.E.L. \& SOUZA-SILVA, J.C., eds. Cerrado, caracterização e recuperação de Matas de Galeria. Planaltina, Embrapa - CPAC, 2001. p.665-687. 
OLIVEIRA, J. R. A.; MENDES, I. C.; VIVALDI, L. Carbono da biomassa microbiana em solos de cerrado sob vegetação nativa e sob cultivo: avaliação dos métodos fumigação-incubação e fumigação-extração. Revista Brasileira de Ciência do Solo, Viçosa, MG, v. 25, n. 5, p. 863-871, 2001.

PRAGANA, R. B. Caracterização Pedológica e Diagnóstico da Qualidade de Solos Sob Plantio Direto na Serra do Quilombo, Sudoeste Piauiense. 2011. Tese (Doutorado em Ciência do Solo) Programa de Pós-Graduação em Ciência do Solo, Universidade Federal Rural de Pernambuco.

SAMPAIO, D. B.; ARAÚJO, A. S. F.; SANTOS, V. B. Avaliação de indicadores biológicos de qualidade do solo sob sistemas de cultivo convencional e orgânico de frutas. Ciência e Agrotecnologia, Lavras, v. 32, n. 2, p. 353-359, 2008.

SILVA, L.G.; MENDES, I.C.; REIS JÚNIOR, F.; FERNANDES, M.F.; MELO, J.T. \& KATO, E. Atributos físicos, químicos e biológicos de um Latossolo de Cerrado em plantio de espécies florestais. Pesq. Agropec. Bras., 44:613-620, 2009.

YEOMANS, J.C.; BREMNER. J.M. A rapid anda precise method for routine determination of organiccarbonoin soil. Commun. SOIL SCI. Plant NA, 19, 1467- 1476. 1988. 